Research Article

\title{
Study of factors of utilisation of antenatal services and awareness among pregnant women in third trimester attending government maternity hospital Warangal, Telangana State, India
}

\author{
L. Niharika*, K. Bhavani
}

Department of Community Medicine, Kakatiya Medical College, Warangal, Telangana State, India

Received: 05 July 2016

Accepted: 19 July 2016

*Correspondence:

Dr. L. Niharika,

E-mail: niharikalakkoju.431@gmail.com

Copyright: (c) the author(s), publisher and licensee Medip Academy. This is an open-access article distributed under the terms of the Creative Commons Attribution Non-Commercial License, which permits unrestricted non-commercial use, distribution, and reproduction in any medium, provided the original work is properly cited.

\begin{abstract}
Background: Understanding the factors affecting the utilization of maternity care during pregnancy and delivery is required. The present study was carried out to find out the awareness and factors associated with utilization of maternal care services.

Methods: A community based observational study was conducted during September to November 2015 on randomly selected antenatal mothers attending Government Maternity hospital, Kakatiya Medical College, Warangal, India. A total of 200 third trimester pregnant women were interviewed using a pre-tested questionnaire regarding utilization and awareness of antenatal services. Statistical analysis: Percentages, Proportions and chi-square test.

Results: A total of 200 antenatal mothers participated in the study. Majority (37.5\%) belonged to the age group of 20 24 years in which most of the antenatal mothers belong to Hindu religion $(86.3 \%$ ), of which $50.7 \%$ lived in a nuclear family. In this study, the percentage of antenatal mother belonging to Upper Lower class was predominant with 26.5\%. Association was also found regarding utilization of antenatal services between age of the mother and literacy of the mother. $83.5 \%$ of the antenatal mothers had taken the recommended two doses of T.T with a complete booster dose, $87.1 \%$ are aware of family planning services, $97.8 \%$ of antenatal mothers are aware of immunization and approximately $95 \%$ of the antenatal mothers are aware of mother craft classes.

Conclusions: The study shows early and wide spread use of antenatal care, but it also reveals that the antenatal visits occur late in the pregnancy. The literacy and age of women has significant bearing on utilization of antenatal care by the pregnant women.
\end{abstract}

Keywords: Antenatal services, Socio-demographic variables, Pregnant mother, Utilization

\section{INTRODUCTION}

Every minute a woman dies as a result of pregnancy or childbirth. Loss per annum of 500,000 women is mind boggling. Thus, maternal mortality continues to be a major public health problem. ${ }^{1}$ About $99 \%$ of all maternal deaths occur in developing countries. The focus on maternal mortality was sharpened when reduction in maternal mortality became one of the eight goals for development in the Millennium Declaration (Goal 5). ${ }^{2}$
The target for MDG 5 is to reduce the maternal mortality ratio (MMR) by three quarters from 1990 to $2015 .^{3}$

Maternal mortality is higher in women living in rural areas and among poorer communities. Young adolescents face a higher risk of complications and death as a result of pregnancy than other women. Skilled care provided before, during and after childbirth can save the lives of women and newborn babies. Between 1990 and 2015, maternal mortality worldwide dropped by about $44 \%$. 
Between 2016 and 2030, as a part of the sustainable development agenda, the target is to reduce the global maternal mortality ratio to less than 70 per 100000 live births. $^{4}$

Current maternal mortality in India is 167 per 100,000 live births. ${ }^{5}$ For effective implementation of the programs, understanding of the factors affecting the utilization of maternity care during pregnancy and delivery is required.

If these factors are correctly identified, the program efforts can be concentrated to increase the acceptance/utilization rates. Therefore, the present study was carried out to find out the factors associated with utilization of maternal care services.

\section{Objectives}

- To relate the various socio-demographic variables with utilization of antenatal services.

- To assess the health seeking behavior patterns existing among pregnant women.

\section{METHODS}

A cross-sectional study was carried out among 200 pregnant women who came for regular antenatal checkups during third trimester at Government maternity hospital, Kakatiya medical college, Warangal by a convenient sampling method over a period of 3 months from September 2015 to November 2015.

Kakatiya Medical College (KMC) is located in Warangal, Telanagana state under the gamut of Kaloji Narayana Rao University of Health Sciences. It is one of the premiere teaching and training public institutions of Telangana state that provides specialist tertiary-care services to patients largely belonging to lower/middle socioeconomic strata of the society with rural and urban backgrounds.

A pre-designed, pre-tested, self-administered questionnaire in English was devised to collect data. The demographic details like age, occupation, education, marital status, BMI, past history, associated diseases, other chronic illness, hereditary factors, habits and lifestyle, health seeking behavior of the respondents were recorded.

Some questions were objective in nature with 'yes' or 'no' answers whereas a few questions were multiplechoice. The pregnant women studied on a voluntary basis and those who were too sick were not included in the study.

All study participants were given a briefing about the objective of the study and were assured about complete confidentiality regarding collection and storage of personal data.

\section{Statistical analysis}

Data were entered into Microsoft Excel and analyzed using the Statistical Package of Social Sciences (SPSS) version-22.0. Statistical significance was set at $\mathrm{P} \leq 0.05$.

\section{RESULTS}

According to Table 1, the mean age of the antenatal mother is 23 years, and the number of third trimester mothers belonging to the age group of 20-24 years is $75(37.5 \%)$, amongst which most of the antenatal mothers belong to Hindu religion $(86.3 \%)$ and $50.7 \%$ lived in nucler families. In this study, a predominant number of third trimester mothers belonged to upper lower class (26.5\%).

Table 1: Socio-demographic profile of the study population.

\begin{tabular}{|ll|}
\hline Socio-demographic profile & Number $(\%)$ \\
\hline Mean age & 23 years \\
\hline Mothers age & \\
\hline$<19$ Years & $38(19 \%)$ \\
\hline 20-24 Years & $75(37.5 \%)$ \\
\hline $25-29$ Years & $51(25.5 \%)$ \\
\hline$>30$ Years & $36(18 \%)$ \\
\hline Religion & \\
\hline Hindu & $173(86.3 \%)$ \\
\hline Muslim & $15(7.9 \%)$ \\
\hline Christian & $12(5.8 \%)$ \\
\hline Family Type & \\
\hline Nuclear & $101(50.7 \%)$ \\
\hline Joint & $96(47.9 \%)$ \\
\hline Extended & $03(1.4 \%)$ \\
\hline & \\
\hline Socio Economic Status & \\
\hline Upper Class & $40(20 \%)$ \\
\hline Upper Middle & $41(20.5 \%)$ \\
\hline Lower middle & $42(21 \%)$ \\
\hline Upper lower & $53(26.5 \%)$ \\
\hline Lower & $24(12 \%)$ \\
\hline Antenatal mother Education & \\
\hline Illiterate & $27(13.5 \%)$ \\
\hline Primary & $35(17.5 \%)$ \\
\hline Secondary & $54(27 \%)$ \\
\hline Intermediate & $48(24 \%)$ \\
\hline Graduate & $33(16.5 \%)$ \\
\hline Post graduate & $3(1.5 \%)$ \\
\hline Husband's education & \\
\hline Illiterate & \\
\hline Primary & \\
\hline Secondary & $(13.6 \%)$ \\
\hline Intermediate & \\
\hline Graduate & \\
\hline Post graduate & \\
\hline
\end{tabular}


As depicted in Table 2, 87.8\% of antenatal mothers are ANC registered and $67.6 \%$ have registered in the $1^{\text {st }}$ trimester while $12.2 \%$ of antenatal mother's registered in $3^{\text {rd }}$ trimester, $89.2 \%$ had antenatal card with $75.5 \%$ antenatal mother's received IFA tablets are predominant. In this study, $74.8 \%$ of the antenatal mother's approach government hospital during health problems.

Table 2: Utilization of antenatal services amongst study population.

\begin{tabular}{|lll|}
\hline Utilization of antenatal services & YES (\%) & NO (\%) \\
\hline Antenatal Care & & $24(12.2 \%)$ \\
\hline ANC Registration & $176(87.8 \%)$ & $65(32.4 \%)$ \\
\hline Time of registration (1 ${ }^{\text {st }}$ Trimester) & $135(67.6 \%)$ & $22(10.8 \%)$ \\
\hline Antenatal card & $178(89.2 \%)$ & $37(18.6 \%)$ \\
\hline Received antenatal care at Government sector & $163(81.4 \%)$ & $68(34.3 \%)$ \\
\hline At least 4 antenatal visits & $131(65.7 \%)$ & $49(24.5 \%)$ \\
\hline IFA Tablets & $151(75.5 \%)$ & $75(37.5 \%)$ \\
\hline Abortions & & $162(81.2 \%)$ \\
\hline Spontaneous & $125(62.5 \%)$ & $162(81.2 \%)$ \\
\hline Uneventful & $38(18.8 \%)$ & $187(93.5 \%)$ \\
\hline MTP & $38(18.8 \%)$ & $50(25.2 \%)$ \\
\hline Approach to treatment during health problems & & $163(81.3 \%)$ \\
\hline Self medication & $13(6.5 \%)$ & $15(74.8 \%)$ \\
\hline Government hospital & $37(18.7 \%)$ & \\
\hline Private Hospital & & \\
\hline
\end{tabular}

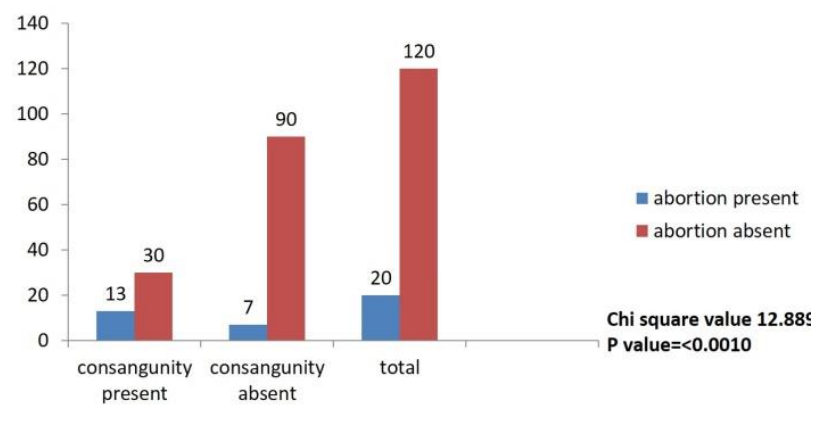

Figure 1: Response regarding consanguinity and abortion.

Figure 1 show there is significant relation between consanguinity and abortion $(\mathrm{p}<0.0010)$, this indicates as consanguinity present there is increase chance of abortion. As Table 3 shows that there is a statistically significant relation between age of the mother with awareness of utilization of antenatal services ( $p$ value $=0.001)$. In this study, there is no statistically significant relation between gravida and awareness of utilization of antenatal services ( $p$-value $=0.682$ ). In this study, there is a statistically significant relationship between literacy of mother with awareness of utilization of antenatal services ( $\mathrm{p}$-value=0.000). In this study, there is no statistically significant relation between socio economic status of mother with awareness of utilization antenatal services ( $\mathrm{p}$-value $=0.984$ ).
Table 3: Age of the mother, gravida, education and socio-economic status of mother with relation to awareness of utilization of antenatal services.

\begin{tabular}{|c|c|c|c|}
\hline \multirow[t]{2}{*}{ Characteritics } & \multicolumn{2}{|c|}{$\begin{array}{l}\text { Antenatal care } \\
\text { services utilization }\end{array}$} & \multirow[t]{2}{*}{ P-value } \\
\hline & Yes & No & \\
\hline \multicolumn{4}{|l|}{ Age of mother } \\
\hline$<19$ & 32 & 6 & \multirow{4}{*}{$\mathrm{P}=0.001$} \\
\hline $20-24$ & 71 & 4 & \\
\hline $25-29$ & 36 & 15 & \\
\hline$>30$ & 34 & 2 & \\
\hline \multicolumn{4}{|l|}{ Gravida } \\
\hline 1 & 86 & 12 & \multirow[t]{2}{*}{$\mathrm{P}=0.682$} \\
\hline$>1$ & 87 & 15 & \\
\hline \multicolumn{4}{|l|}{ Literacy of mother } \\
\hline Illiterate & 22 & 5 & \multirow[b]{5}{*}{$\mathrm{P}=0.000$} \\
\hline Primary & 28 & 7 & \\
\hline Secondary & 53 & 1 & \\
\hline Intermediate & 40 & 8 & \\
\hline Graduate/diploma & 30 & 6 & \\
\hline \multicolumn{4}{|c|}{ Socio economic status } \\
\hline Class 1 & 34 & 6 & \multirow[b]{5}{*}{$\mathrm{P}=0.984$} \\
\hline Class 2 & 35 & 6 & \\
\hline Class 3 & 36 & 6 & \\
\hline Class 4 & 47 & 6 & \\
\hline Class 5 & 21 & 3 & \\
\hline
\end{tabular}


Table 4: Regarding response on T.T Doses.

\begin{tabular}{|ll|}
\hline T.T. Doses & Percentage \\
\hline Nil & $2.2 \%$ \\
\hline 1 dose & $6.50 \%$ \\
\hline 2 dose & $7.90 \%$ \\
\hline Booster dose & $83.50 \%$ \\
\hline
\end{tabular}

As Table 4 shows that, $83.5 \%$ of the antenatal mother's had taken complete 2 doses of T.T. with a complete booster dose. As Table 5 shows that $78.4 \%$ antenatal mothers are aware of complications in antenatal period, $87.10 \%$ of antenatal mothers are aware of breast feeding, $87.1 \%$ are aware of family planning services and most of the antenatal mothers are aware of warning signs of antenatal period.

Table 5: Regarding awareness in antenatal period.

\begin{tabular}{|lcc|}
\hline Awareness & Yes (\%) & No (\%) \\
\hline Awareness in antenatal period & & $21.60 \%$ \\
\hline Complications & $78.4 \%$ & $12.90 \%$ \\
\hline Breast feeding & $87.10 \%$ & $12.90 \%$ \\
\hline Care of the baby & $87.10 \%$ & $11.50 \%$ \\
\hline Need for cleanliness at time of delivery & $88.50 \%$ & $12.90 \%$ \\
\hline Family planning & $87.10 \%$ & \\
\hline Warning signs & & $20.1 \%$ \\
\hline Swelling of Feet & $77.7 \%$ & $19.4 \%$ \\
\hline Fits & $80.6 \%$ & $21.6 \%$ \\
\hline Headache & $78.4 \%$ & $21.6 \%$ \\
\hline Blurring of Vision & $78.4 \%$ & $19.4 \%$ \\
\hline Bleeding/Discharge per vagina & $80.6 \%$ & \\
\hline
\end{tabular}

Table 6: Mother craft education.

\begin{tabular}{|lll|}
\hline Craft education & Yes (\%) & No (\%) \\
\hline Nutrition & $93.5 \%$ & $6.5 \%$ \\
\hline Advice on Child hygiene & $93.5 \%$ & $6.5 \%$ \\
\hline Cooking demonstrations & $18.7 \%$ & $81.3 \%$ \\
\hline Family Planning & $87.1 \%$ & $12.9 \%$ \\
\hline Family Budgeting & $16.5 \%$ & $83.5 \%$ \\
\hline Immunization of new born & $97.8 \%$ & $2.2 \%$ \\
\hline Use of Contraceptives & $32.4 \%$ & $57.6 \%$ \\
\hline
\end{tabular}

As Table 6 shows that $97.8 \%$ of antenatal mothers are aware of immunization and approximately $95 \%$ of the antenatal mothers are aware of mother craft classes. In this study $32.4 \%$ of antenatal mothers are aware of use of contraceptives.

\section{DISCUSSION}

The present study was carried out among pregnant women in the third trimester residing at government maternity hospital K.M.C, Warangal. A total of 200 pregnant women were interviewed and analyzed for ANC services utilization in $3 \mathrm{rd}$ trimester.

Adequate ANC service utilization rate in the study: $78 \%$ ANC cases are registered and $65.7 \%$ pregnant women are have least 4 visits, Similarly according to NFHS-4 state fact of Telanagana state, women with at least 4 antenatal visits are $75 \%$, Whereas in NFHS-3, pregnant women having at least 3 or more antenatal visits in India are $52 \% .^{5,6}$ Another study done by Banerjee B also estimated that $93 \%$ women have 3 antenatal checkups.

In other study done by Singh and Arora also noted that $34.9 \%$ cases had 3 or more antenatal visits. ${ }^{7,8}$

In this study, association of utilization of ANC services by women was not found statistically significant with socio economic status but education and age of mother were found influencing factors on ANC utilization. Similar results were observed in a study done by Chandhoik $\mathrm{N}$ et al i.e. proportion of women obtaining antenatal care services increases with increasing age. ${ }^{9}$

Various socio demographic factors of family show a good response with utilization of antenatal services. It shows the impact of education on awareness and utilization of services. $83.5 \%$ of pregnant women had received TT booster dose and $6.5 \%$ received $1 \mathrm{TT}$ dose and $2.2 \%$ pregnant didn't receive single dose of TT compared to $77.9 \%$ of pregnant women had 1 received TT2 / booster and $13.6 \%$ had not taken a single dose of TT in a study done by Singh $\mathrm{P}$ et al. ${ }^{10}$

It is important note to that more than $60 \%$ of women claimed that they heard about the service by health extension workers. This is an important finding because it heralds that mothers have trust on health extension 
workers. As predicted by other studies elsewhere, majority of the respondents sensitization (72.04\%) was by health workers; if health workers are encouraged and empowered, this would make ANC awareness better. ${ }^{11-16}$

The literacy of women and age of the mother has significant effect on antenatal care of pregnant women. $12.2 \%$ of pregnant women's have registered in third trimester. Most $(57.6 \%)$ of the eligible couples are unaware of contraceptive. According to NFHS-4 Telangana state fact, eligible couples with unmet needs of family planning were $7.3 \% .^{5}$ Majority of abortions were seen in consanguineous marriages.

\section{Limitations}

One of the limitations of the study was the use of a convenient sample. It limited the generality and ability of the study. In addition, it is important to remember that the results of this study are dependent upon the accuracy of the responses.

\section{CONCLUSION}

The study shows early and widespread use of antenatal care, but it also reveals that the antenatal visits occur late in the pregnancy.

Most of the eligible couples are with unmet needs of family planning. The literacy and age of women has significant bearing on antenatal care of pregnant women and increased incidence of abortions was seen in consanguinous marriages. Thus, measures should be adopted for improving female literacy and preventing consanguinity in marriages.

\section{Recommendations}

Increase the ANC utilization services and improve at least 4 visits by $100 \%$. This means there is need of more health education awareness among pregnant mothers and their family. Educate and council the mothers and their parents not to encourage for consanguinity marriage and to reduce the prevalence of abortions.

Educate and council the public and antenatal mother's by ANM workers regarding awareness of utilization of antenatal services. The literacy of women has significant bearing on antenatal care of pregnant women. Thus, measures should be adopted for improving female literacy.

\section{ACKNOWLEDGEMENTS}

Authors are thankful to Dr. Punam Kumari Jha, Professor and Head, and Dr. K. J. Kishore Kumar, Associate Professor, Depertment of Community Medicine, Kakatiya Medical College, Warangal. We also acknowledge the help and support of pregnant women during the study.
Funding: No funding sources

Conflict of interest: None declared

Ethical approval: The study was approved by the Institutional Ethics Committee

\section{REFERENCES}

1. WHO, UNICEF, UNFPA. Maternal Mortality in 2000: Estimates Developed by WHO, UNICEF, UNFPA. Geneva: WHO, 2003.

2. Ronsmans C, Graham WJ. Lancet maternal survival series steering group: Lancet. 2006;368:1189-200.

3. New York: United Nations; 2000. United Nations General Assembly. United Nations Millennium Declaration. A/RES/55/2.

4. WHO. Global Health observatory data: Maternal mortality. 2015, available from: http://www.who.int/ gho/ maternal_health/ mortality/ maternal_mortality_text/en/

5. National family health survey (NFHS-4). Telangana state fact sheet, India: 2015-16. Pg.1-6. available from: http://rchiips.org/ nfhs/ pdf/ NFHS4/ TG_FactSheet.pdf.

6. National family health survey (NFHS-3). India: [online] 2007; vol.1. pg.192-222. available from: http://www.nfhsindia.org [accesses on 14 October 2015].

7. Banerjee B. Maternal care rendered at urban health center of a metropolitan city: Indian $\mathrm{J}$ community medicine 2006;31(3):183-4.

8. Singh A, Arora AK. The changing profile of pregnant women and quality of antenatal care in rural north India. Indian $\mathbf{J}$ Community Med. 2007;32(2):135-6.

9. Chandhiok N, Dhillon BS, Kambo I, Saxena NC. Determinants of antenatal care utilization in rural areas of India: A cross-sectional study from 28 districts (An Indian Council of Medical Research task force study). Journal of Obstetrics and Gynecology of India. 2006;56(1):47-52.

10. Singh P, Yadav RJ. Antenatal care of pregnant women in India: Indian $\mathbf{J}$ Community Med 2000;25(3):112-17.

11. Agarwal P, Singh MM, Garg S. Maternal healthcare utilization among women in an urban slum in Delhi. Indian J Community Med 2007;32:203-05.

12. Jejeebhoy SJ. Maternal mortality and morbidity in India: priorities for social sciences research. J Family Welfare 1997;42(2):30-51.

13. Mother-baby package: Implementing safe motherhood in countries. World Health Organization: Geneva. 1994.

14. National Population Policy - 2000. Department of family welfare.Ministry of Health and Family Welfare. Government of India, New Delhi. 2000.

15. Park JE, Park K. Text Book of Preventive and Social Medicine, 22nd edition M/s. Banarsidas Bhanot Publishers: Jabalpur, India: 2013;523-9, 557-2. 
16. Ray SK, Mukherjee B, Dobe M, Sengupta D, Ghosh $\mathrm{M}$, and Chaudhuri N. Utilization of maternal services in West Bengal. Indian Pediatrics. 1993;30:351-54.
Cite this article as: Niharika L, Bhavani K. Study of factors of utilisation of antenatal services and awareness among pregnant women in third trimester attending government maternity hospital Warangal, Telangana State, India. Int J Community Med Public Health 2016;3:2291-6. 